\title{
Durum Wheat Straw as Enveloping and Insulating Material in Buildings: Is It Sustainable? Findings from a Comparative Energy and Environmental Assessment of Alternative Solutions
}

\author{
Carlo Ingrao $^{1}$ and Antonio Messineo ${ }^{2}$ \\ ${ }^{1)}$ University of Foggia, Foggia, Italy. \\ ${ }^{2)}$ Kore University of Enna, Enna, Italy.
}

E-mail: carlo.ingrao@unifg.it; E-mail: messineo.ingegneria@gmail.com

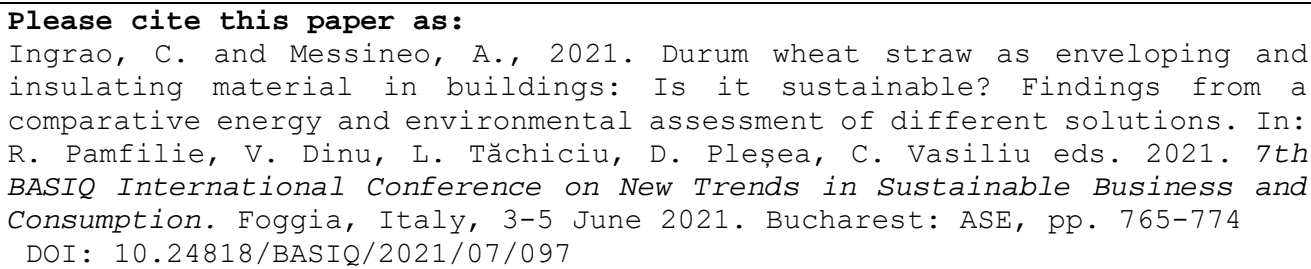

\begin{abstract}
Application of Life Cycle Assessment (LCA) in the building sector is usually performed on the envelope scale, mainly for comparison of several sample-solutions, and provides in-depth analyses of the related energy and environmental performances. Doing so enable identification of the solutions that perform best in energy and environmental terms, and that are determined to be suitable for construction of sustainable buildings.
\end{abstract}

In this context, the objective of this study is to perform a comparative energy and environmental assessments of three external-wall samples that were designed using different sophistication rates in terms of assembly technologies and component materials.

The samples considered were properly designed as the initial step prior to the energy and environmental assessment. In particular, two 'unconventional' enveloping solutions providing the use of natural and recycled materials (durum wheat straw and recycled polyethylene terephthalate) in easy-disassembly and recyclable compositions with one conventional façade.

Results show that the unconventional wall samples perform quite well in both energy and environmental terms, and can be considered as clean construction solutions that are valid candidates for the design of environmentally sustainable and low-energy demanding buildings. The straw-based solution is the one that performs best from an energy and environmental perspective. The choice of one or the other is, however, strictly depending upon the type of buildings that is designed, and the architectural and structural requirements it needs to fulfil.

Finally, the authors believe that the study provides helpful insights on the environmental sustainability of eco-friendly materials and technologies, that can contribute to enhancing the specialised knowledge in the field and to supporting practitioners in similar LCA applications developed in the years following.

Keywords: Buildings; Wall compositions; Recycled material; Natural material; Life Cycle Assessment; Energy efficiency; Environmental sustainability.

DOI: 10.24818/BASIQ/2021/07/097 


\section{Introduction}

To face the current challenges of energy consumption, climate change and resources depletion, the design of buildings should be centred upon taking environmentally sustainable solutions that allow for reduction of material and energy consumption (La Rosa et al., 2014). Those should be designed with a Life Cycle Thinking (LCT) approach to decrease the environmental impacts, that are associated not only with the building construction phase but, also, with the down-stream phases of use/maintenance and end-of-life that are included within the buildings' life cycles.

In this context, Life Cycle Assessment (LCA) can be used to orient the architectural design to maximising the environmental-sustainability and energy-efficiency rates of buildings throughout their life cycles (Ingrao et al., 2016, 2018a).

LCA has evolved significantly over the past decades, mainly thanks to the valuable work carried out by several research groups on the global scale, and so has become more systematic and robust for estimation of the environmental hotspots of products or complex systems, from the moment it is designed to the moment it gets to the end of its service life and becomes a waste, or an ensemble of wastes, to be treated (Jeswani et al., 2010). Currently, LCA is used for selection of products and processes, in the phases of design and optimisation, and is often coupled with simulation techniques and design tools. In this way, companies can be fully informed on the environmental consequences of their actions, both inside and outside the company gate (Compagno et al., 2014).

Together these developments have placed LCA in a central role to identify cradle-to-grave impacts of materials, products and energies, as well as of the complex systems in which they are utilised and processed. In the building sector, LCA allows for evaluation of important aspects like the energy embedded in the building materials utilised and the operational energy, the transportation of those materials to the construction yards, as well as the associated emissions of Greenhouse Gases (GHGs) (Malmqvist et al., 2011).

When LCA is used as a support-tool for building design, it should be coupled with an in-depth energy analysis, for application on the envelope scale. This practice is well-accepted in the literature and should be followed for all parts of the enveloped, namely the perimeter and the inside walls, the groundfloor, the halfway-floors (for multi-storey buildings only) and the roof, through life cycle evaluations of several solutions. These are generally represented by samples characterised by a one square metre surface and a thickness which depends upon the composition designed. Comparison of the compositions hypothesised enable identification of the most energy performing and environmentally sustainable ones, that then are used for the modelling of the building life cycle by considering the related square metres installed (Ingrao, et al., 2016, 2018a).

In this context, this study was aimed at performing energy and environmental life cycle comparative assessments of three external wall samples that are characterised by different rates of sophistication in terms of assembly technologies and component materials utilised. According to the authors, the importance of energy-environmental studies like the one discussed in this paper is linked to the fact that the way an external wall is designed and assembled influences the consumption of the building operation energy, the environmental sustainability of the entire building's life cycle, and the well-being of the building's users. So, as also proven by the subject literature, the message that the authors wish to convey to readers through this manuscript is that due attention needs to be paid upon the building envelope if acceptable levels of energy performance, environmental sustainability, and human health and safety are desired to be achieved.

\section{Materials and methods}

The study reports upon a comparative Life Cycle Assessment (LCA) of a set of building envelope samples, to highlight those performing best in terms of energy efficiency and environmental sustainability. For this purpose, the study was carried out according to the subject International standards ISO (2006 a, b), which means that it was articulated in the three main phases of goal and scope definition, life cycle inventory, life cycle impact assessment. 
Description of the designed wall composition sample

For the comparative analysis, three wall composition samples were designed in a way for them to comply with the thermal transmission limits foreseen for the area of interest. It was assumed that those compositions are implemented in in the municipality of Piazza Armerina within province of Enna (the smallest city of Sicily located practically in its barycentre). With regard to the Italian climate classification, as for $70 \%$ of the Enna municipalities, Piazza Armerina falls within a 'D' climatic zone. Fig. 1 shows the thermal transmittance limits for all the Italian territory, from which it is possible to extract those for the $D$ climatic-zone.

Actually, the three wall composition samples were designed with the aim of furthering energy performance and environmental sustainability of innovative building solutions compared with a basic solution that is representative of the current building construction practice in the Sicilian region. Those compositions were depicted in Fig. 2, with indications of the values of thickness and thermal transmittance for single-layer and for the entire composition; the thermal transmittance was calculated based upon the ISO (2007).

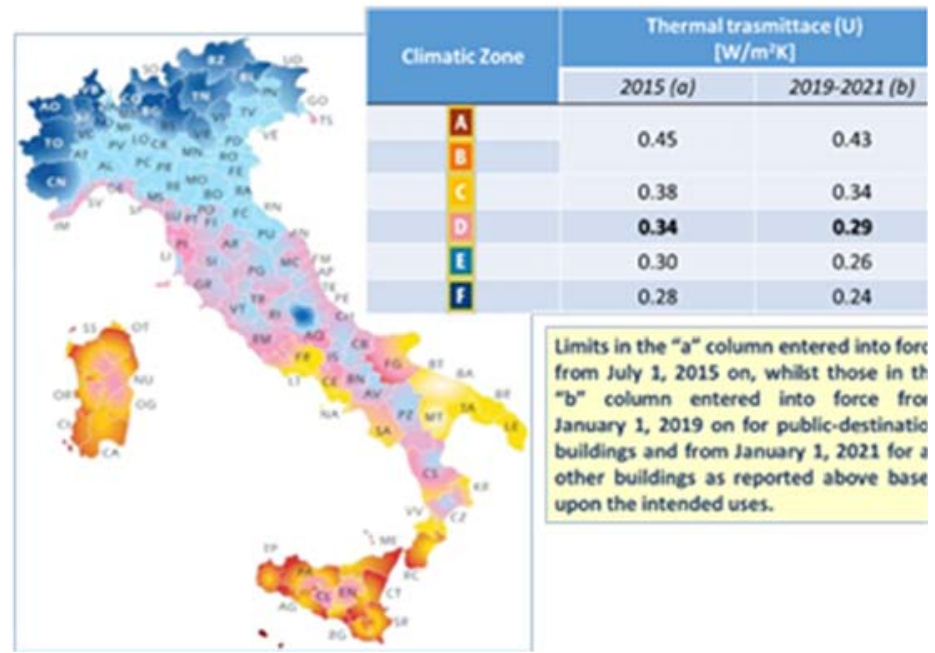

Figure no. 1. Italian climatic zones and related thermal transmittance limits for external walls.

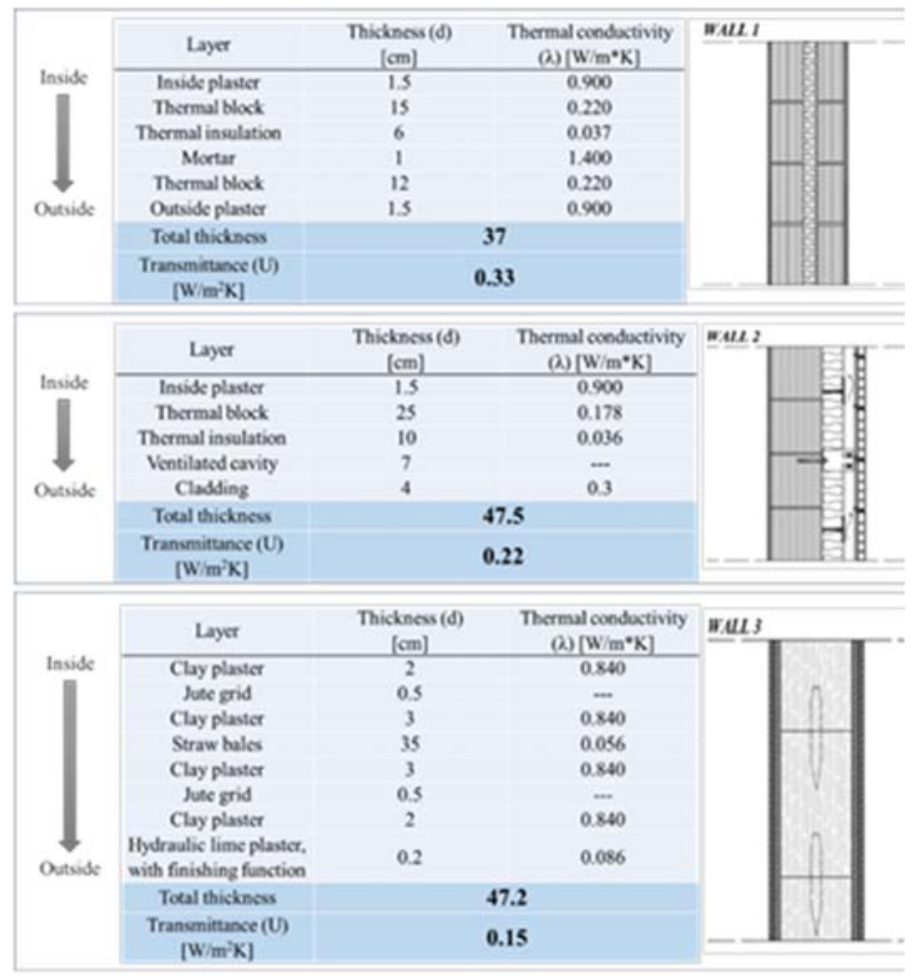

Figure no. 2. Thickness and thermal conductivity by layer, including the total thickness and the thermal transmittance for three wall composition samples assessed in this paper. In wall 2, the thermal insulation is realised using panels made out of recycled Polyethylene Terephthalate (R-PET), whose industrial production was environmentally investigated by Ingrao, et al. 
In particular, as regards the ventilated façade, for calculation of the thermal transmittance the air cavity's thermal resistance was neglected, considering the resistance to the external surface as the value related to still air. This approach is widespread in the literature for a precautionary modelling of ventilated facades, not taking into account their positive contribution during the summer period (Ingrao et al., 2016). The values of thermal conductivity of the homogeneous layers and of equivalent conductivity of the non-homogeneous layers were declared by the manufacturers of each component material and, in the absence of this, the authors used the thermal properties proposed by the Italian reference standard (ISO, 1994).

\section{Goal and scope definition}

This can be considered as the starting phase in any LCA elaboration, and provides the identification of the objectives of the study and the limits of the system investigated in order to avoid neglecting relevant parts of it.

In this context, the aim of this study was to perform a comparative LCA of the three layer sets presented in the previous sections, and to highlight the most relevant inventories and environmental impacts.

In particular, the study was conducted by comparing two unconventional solutions with a conventional one, so to contributing to understanding if it is environmentally worth utilising more sophisticated assembly technologies in combination with recycled insulation materials (wall 2), and natural thermalinsulation and finishing materials (wall 3). In particular, it was provided to use R-PET fibre mats because they are characterised by thermal insulation performance rates that are quite comparable with those of other more widespread conventional materials (Ingrao et al., 2014, 2016). Durum Wheat (DW) straw cultivation was planned for usage in wall 2 as it is highly produced in - and so is highly representative of - the study area (Chinnici et al., 2015). In addition to this, it is increasingly used for unconventional applications, like in buildings, other than the most widespread use as animal bedding or feeding. Those applications contribute to improving the environmental sustainability of farming activities in a life cycle perspective, and enable extracting some of the largest value that is contained within straw.

As part of this phase, the functional unit (FU) was defined to be $1 \mathrm{~m}^{2}$ of wall, with a 50 -year service life, as also indicated by Pulselli et al. (2009) and Rossi et al. (2012).

With regard to the system boundaries, a "cradle-to-cradle" approach was considered as, for some components, the authors explored to reuse them as such or to recycle them, so reducing them back to the materials which they consisted of. For the assessment, the system boundaries were subdivided into four subsystems, as depicted in Fig. 3.

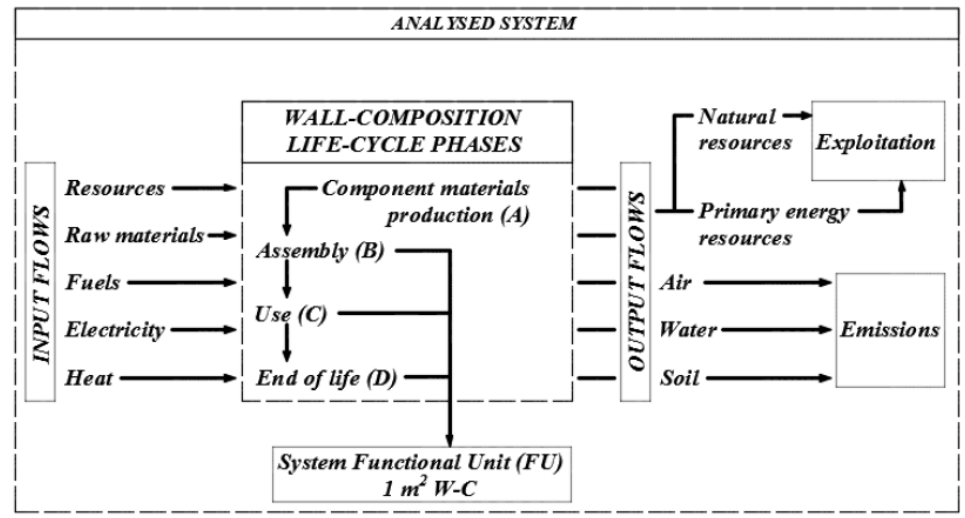

Figure no. 3. The figure shows the boundaries of the system investigated

\section{Life Cycle Inventory}

As part of the inventory phase, input and output flows were analysed starting from data collection and elaboration. In particular, since particularly specific systems were evaluated, priority was given to the use of primary data deriving from the design of the three wall compositions in terms of type and 
quantity of the materials utilised. Furthermore, secondary data were taken from international databases such as Ecoinvent, and included the extraction of resources, the production of materials and energy, as well as the life cycles of the means involved in the input material acquisition. In addition to this, previously studies were accessed: in particular, data regarding the production of the recycled-PET panel used for thermal insulation of wall 2 was extrapolated from Ingrao et al. (2014), whilst straw was modelled as a co-product of DW cultivation in the same area of Sicily in which the wall were supposed to be installed. Primary data associated with the joint production of DW grains and straw were collected in collaboration with local farmers and producers by Ingrao et al. (2018b), and were published in the literature: those data were extracted from that paper, and were used for this assessment development.

Overall, data collection and processing were performed for each of the four subsystems which the system was broken down into, namely material preparation and acquisition, assembly of the three wall compositions, followed by its use and end-of-life. Moreover, data collection was carried out constantly accessing the Ecoinvent software, to check the need to create processes and raw materials that were actually missing in the database. Fortunately, it was found that all supportive data needed were already included within Ecoinvent, thereby avoiding creating new items or making assumptions and hypotheses for using secondary data within the database.

Finally, the following sections reports detailed discussion of the data and methodological approach used for the inventory analysis development.

\section{Wall composition assembly from raw material preparation}

In this research, the assembly phase of the three wall composition samples depicted in Fig. 3 was setup to include production of the component materials. Therefore, the related modelling was made by considering $1 \mathrm{~m}^{2}$ of wall composition as FU and accounting for the component materials in stake, based upon both surface mass $\left(\mathrm{kg} / \mathrm{m}^{2}\right)$ and transportation from the manufacturer to the Building Construction Yard (BCY) for installation. Input transport flow values were not reported for reasons of space: it can be asserted that all material inputs, but the recycled-PET panels, are supplied from manufacturers in the around of $50 \mathrm{~km}$. By contrast, the recycled-PET panels are supply travelling for a nearly $1600 \mathrm{~km}$ distance. All the elaborated data were listed in Table 1. From the table, it can be observed that the three walls have comparable mass values in the range $185-190 \mathrm{~kg} / \mathrm{m}^{2}$.

Table no. 1. Relevant input data and related total mass per unit area of the three wall compositions under study

\begin{tabular}{|c|c|c|c|c|c|}
\hline Composing material & $\begin{array}{l}\text { Thickness } \\
{[\mathrm{cm}]}\end{array}$ & $\begin{array}{l}\text { Dimensions } \\
{[\mathrm{cm}]}\end{array}$ & $\begin{array}{l}\text { Weight by } \\
\text { piece [kg] }\end{array}$ & {$\left[\mathrm{kg} / \mathrm{m}^{2}\right]$} & $\begin{array}{l}{[\mathbf{N} . \quad \text { of }} \\
\left.\text { pieces } / \mathbf{m}^{2}\right]\end{array}$ \\
\hline Plaster & 1.5 & - & - & 2.25 & - \\
\hline Thermal block (bricks) & 15 & $15 \times 25 \times 25$ & 5.9 & 91 & 15.4 \\
\hline Thermal insulation & 6 & $6 \times 100 \times 50$ & 0.45 & 0.9 & 2 \\
\hline Mortar & 1 & - & - & 2 & - \\
\hline Thermal block & 12 & $12 \times 25 \times 25$ & 4 & 61.6 & 15.4 \\
\hline Plaster & 1.5 & - & - & 2.25 & - \\
\hline $\begin{array}{l}\text { Mortar for brick } \\
\text { installation }\end{array}$ & - & - & - & 27 & - \\
\hline \multicolumn{2}{|l|}{ Total mass (WALL 1) } & \multicolumn{2}{|l|}{187} & \multicolumn{2}{|l|}{$\mathrm{kg} / \mathrm{m}^{2}$} \\
\hline Composing material & $\begin{array}{l}\text { Thickness } \\
\text { [cm] }\end{array}$ & $\begin{array}{l}\text { Dimensions } \\
{[\mathrm{cm}]}\end{array}$ & $\begin{array}{l}\text { Weight by } \\
\text { piece [kg] }\end{array}$ & {$\left[\mathrm{kg} / \mathrm{m}^{2}\right]$} & $\begin{array}{l}{[\mathbf{N} . \quad \text { of }} \\
\left.\text { pieces } / \mathbf{m}^{2}\right]\end{array}$ \\
\hline Plaster & 1.5 & - & - & 2.25 & - \\
\hline Thermal block (bricks) & 25 & $25 \times 25 \times 25$ & 8.7 & 134 & 15.4 \\
\hline Thermal insulation & 10 & $10 \times 100 \times 50$ & 1.5 & 3 & 2 \\
\hline Ventilated air cavity & 1 & - & - & - & - \\
\hline Cladding & 4 & $4 \times 100 \times 25$ & 7.5 & 30 & 4 \\
\hline $\begin{array}{l}\text { Aluminium structure for } \\
\text { cladding support }\end{array}$ & - & - & - & 2 & - \\
\hline
\end{tabular}


BASIQ INTERNATIONAL CONFERENCE

\begin{tabular}{|c|c|c|c|c|c|}
\hline $\begin{array}{l}\text { Mortar for } \text { brick } \\
\text { installation }\end{array}$ & - & - & - & 13.5 & - \\
\hline \multicolumn{2}{|l|}{ Total mass (WALL 2) } & \multicolumn{2}{|l|}{184.75} & \multicolumn{2}{|l|}{$\mathrm{kg} / \mathrm{m}^{2}$} \\
\hline Composing material & $\begin{array}{l}\text { Thickness } \\
\text { [cm] }\end{array}$ & $\begin{array}{l}\text { Dimensions } \\
{[\mathrm{cm}]}\end{array}$ & $\begin{array}{ll}\text { Weight } & \text { by } \\
\text { piece }[\mathrm{kg}] & \end{array}$ & {$\left[\mathrm{kg} / \mathrm{m}^{2}\right]$} & $\begin{array}{l}{[\mathbf{N} . \quad \text { of }} \\
\left.\text { pieces } / \mathbf{m}^{2}\right]\end{array}$ \\
\hline Clay plaster & 2 & - & - & 28 & - \\
\hline Jute grid & 0.5 & $0.5 \times 200 \times 200$ & 14.6 & 7.3 & 0.5 \\
\hline Clay plaster & 3 & - & - & 42 & - \\
\hline Straw bales & 35 & $35 \times 50 \times 120$ & 18.9 & 31.5 & 1.2 \\
\hline Clay plaster & 3 & - & - & 42 & - \\
\hline Jute grid & 0.5 & $0.5 \times 200 \times 200$ & 14.6 & 7.3 & 0.5 \\
\hline Clay plaster & 2 & - & - & 28 & - \\
\hline $\begin{array}{l}\text { Lime mortar for the wall } \\
\text { finishing }\end{array}$ & 0.2 & - & - & 2.8 & - \\
\hline Wooden picket & - & $5 \times 35 \times 5$ & 0.324 & 0.648 & 2 \\
\hline \multicolumn{2}{|l|}{ Total mass (WALL 3) } & \multicolumn{2}{|l|}{189.55} & \multicolumn{2}{|l|}{$\mathrm{kg} / \mathrm{m}^{2}$} \\
\hline
\end{tabular}

Finally, the assembly phase modelling was complemented with the estimation of the energy consumption associated with the on-site installation activities: electricity and fuel use from different construction equipment and activities were considered for that purpose. In this regard, considering the subject literature Ingrao et al. (2016) highlighted that such an energy consumption generally varies between $1 \%$ and $4 \%$ of the total energy embedded within the construction materials utilised. Therefore, for the first two masonry samples, it was appropriate to assume an average value of $2 \%$. As regards the third sample, electricity consumption is implied for the use of a construction site mixer for the installation of the extrados finishing layer, and a $0.224 \mathrm{kWh} / \mathrm{m}^{2}$ was estimated.

\section{Electricity consumption associated with the 50-year operation of the walls}

This phase was modelled as the amount of electricity consumed for indoor heating and cooling, considering the heat losses and gains through the analysed walls both in winter and summer. The related energy analysis was carried out following Stewart (1948), Pizzetti (1986), Ciampi et al. (2003), and Ingrao et al. (2016), and results shown in Table 2 were obtained.

Table no. 2. Values of operational electricity with a 50-year temporal horizon

\begin{tabular}{|l|l|l|l|}
\hline Wall & $\mathbf{E}_{\text {e(cooling) }}\left[\mathbf{k W h} / \mathbf{m}^{\mathbf{2}}\right]$ & $\mathbf{E}_{\text {e(heating) }}\left[\mathbf{k W h} / \mathbf{m}^{\mathbf{2}}\right]$ & $\mathbf{E}_{\text {e(tot) }}\left[\mathbf{k W h} / \mathbf{m}^{\mathbf{2}}\right]$ \\
\hline 1 & 44.15 & 54.31 & 98.45 \\
\hline 2 & 29.15 & 36.21 & 65.35 \\
\hline 3 & 20.29 & 24.69 & 44.97 \\
\hline
\end{tabular}

From the calculated values of thermal transmittance (U) reported in Fig. 3, there is evidence that all of them are in compliance with the limit established for the Italian Climate Zone D, namely $0.34 \mathrm{~W} / \mathrm{m}^{2}$ $\mathrm{K}$, and both wall 2 and 3 are so energy performant that they meet the more restricted limit (see Fig. 2).

\section{End of life}

This phase is about disposing of the wall samples, and treating the component materials. Already in the design phase, it is necessary to select less impacting materials and assembly technologies that enable separating the various elements, so that the latter can be recycled separately into valued-added secondary raw materials.

In this paper, the end-of-life was modelled on the basis of the composition of each wall analysed, using background data, and on the local waste-management practice. In particular, different end-of-life scenarios were considered for the dismantle-derived materials, namely landfill, recycling, or re-use. Results from this phase development were shown in Table 3. 
Table no. 3. Values of operational electricity with a 50-year temporal horizon

\begin{tabular}{|c|c|c|c|c|}
\hline Wall & $\begin{array}{l}\text { Composing } \\
\text { elements }\end{array}$ & $\begin{array}{l}\text { Quantity (kg) } \\
\text { per } \mathbf{m}^{2} \text { of wall } \\
\text { sample }\end{array}$ & $\begin{array}{l}\text { Percentage } \\
\text { incidence on the } \\
\text { whole wall }[\%]\end{array}$ & Disposal scenario \\
\hline 1 & All & 187 & 100 & \multirow{10}{*}{$\begin{array}{l}\text { Regeneration for the production } \\
\text { of filling material for road } \\
\text { embankments, in a special } \\
\text { treatment plant }\end{array}$} \\
\hline \multirow[t]{5}{*}{2} & Bricks & 134 & 72.53 & \\
\hline & Claddings & 30 & 16.24 & \\
\hline & Plaster & 2.25 & 1.22 & \\
\hline & Mortar & 13.5 & 7.31 & \\
\hline & $\begin{array}{l}\text { Recycled-PET } \\
\text { panel }(10 \%)\end{array}$ & 0.3 & 0.16 & \\
\hline \multirow[t]{4}{*}{3} & Clay plaster & 140 & 73.86 & \\
\hline & Jute grid & 14.6 & 7.7 & \\
\hline & $\begin{array}{l}\text { Outdoor } \\
\text { finishing }\end{array}$ & 2.8 & 1.48 & \\
\hline & $\begin{array}{l}\text { Wooden } \\
\text { material }\end{array}$ & 0.648 & 0.34 & \\
\hline \multirow[t]{2}{*}{2} & $\begin{array}{l}\text { Recycled-PET } \\
\text { panel }(90 \%)\end{array}$ & 2.7 & 1.46 & \multirow[t]{2}{*}{ Recycling } \\
\hline & $\begin{array}{l}\text { Aluminium } \\
\text { frame }\end{array}$ & 2 & 1.08 & \\
\hline 3 & Straw bales & 31.5 & 16.62 & Re-use as animal feed \\
\hline
\end{tabular}

\section{Results and discussions}

The Life Cycle Impacts Assessment (LCIA) phase was conducted using a joint mid-/end-point approach using Impact 2002+ as the assessment method (Jolliet et al., 2003), that is part of the Simapro software that was used for this study development. Results were expressed in the form of weighing points measuring the environmental damage affected. From the assessment, it was found that the three walls presented the following points: $0.0415 \mathrm{pt}$ (wall 1), $0.0255 \mathrm{pt}$ (wall 2), $0.0257 \mathrm{pt}$ (wall 3). It is therefore clear that the two unconventional construction types are nearly $40 \%$ less impacting compared with the conventional one, consequently to a better behaviour in energy efficiency and environmental impact terms. The obtained results were divided into the three phases composing the life cycle system as shown in Table 4.

Table no. 4. Comparison of the three walls' environmental profiles based upon with environmental damage results per single life-cycle phase

\begin{tabular}{|c|c|c|c|}
\hline \multirow{2}{*}{ WALL } & \multicolumn{3}{|c|}{ Life cycle phases } \\
\cline { 2 - 4 } & Assembly & Use & End-of-life \\
\cline { 2 - 4 } & \multicolumn{3}{|c|}{ Weighing points } \\
\hline 1 & 0.0194 & 0.0202 & 0.0019 \\
\hline 2 & 0.0189 & 0.0134 & -0.0068 \\
\hline 3 & 0.0268 & 0.0074 & -0.0085 \\
\hline
\end{tabular}

From the table, there is evidence that, in the assembly phase the building envelope made with straw (Wall 3) performed worst, due to the impacts associated with agricultural production and processing of straw and jute. With a score of $0.0151 \mathrm{pt}$ and $0.0056 \mathrm{pt}$ respectively, jute and straw represent $56.34 \%$ and $20.78 \%$ of the damage associated with the assembly phase $(0.0268 \mathrm{pt})$. In addition to this, with a total damage of $0.0207 \mathrm{pt}$, they contribute to the damage overall associated with the wall $(0.0257 \mathrm{pt})$ for around $80 \%$. However, a low value in the phase of use of the wall and a negative contribution during the end-of-life phase make the total score of this constructive solution not only quite comparable to that of the ventilated wall, but also far better than the conventional one. This wall has a total electricity 
consumption during the use phase equal to $44.97 \mathrm{kWh} / \mathrm{m}^{2}$, which leads to having a weighing point in the use phase which is about half of the other two casings analysed. As for the end-of-life phase, the negative contribution is due to the possibility of using straw as substitute in livestock feeding, thereby avoiding relevant impacts associated with conventional feed production. The negative contribution in the end-of-life phase of the ventilated wall is instead due to the type of construction adopted. In fact, the ventilated chamber is of the 'dry' type, which means that a properly designed aluminium frame was installed for layer assembly instead of the conventional mortars: doing so enable separating and recycling both the R-PET panel and the aluminium frame. As clearly shown from Table 7, wall 2 shows the best performance in the assembly phase: this should be attributed to the environmental benefits associated with the application of an insulation panel that is produced using an $80 \%$ recycled-PET granulate.

Finally, with regard to wall 1 , while this satisfies the thermal transmittance limit of $0.34 \mathrm{~W} / \mathrm{m}^{2} \mathrm{~K}$, shows the worst environmental performance. This derives from the worse energy performance in the use phase resulting in higher environmental damages, and from the environmental burdens associated with the wall treatment disposal being greater than the benefits obtainable from generation of a filling material substitute. In addition to this, it is the only wall among the three assessed having the environmental damage associated with the use phase exceeding - though slightly - that associated with the production one.

Entering into the merits of the damage categories being affecting by the wall in its life cycle, the values reported in Fig. 4 were obtained.

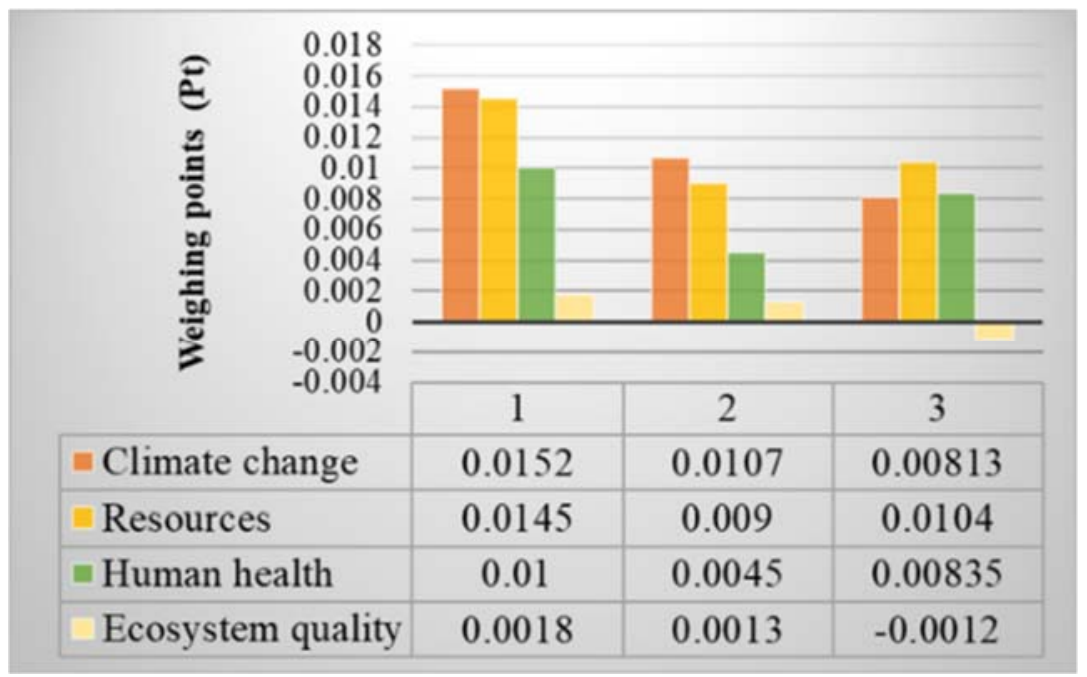

Figure no. 4. Comparison of the three walls analysed, based upon weighing results for the four damage categories considered by Impact $2002+$.

The assessment was then extended to the details of the substances emitted and primary-energy resourced consumed associated with the damage categories that are most affected and so can be considered as most representative of the walls' environmental profiles, namely 'climate change', 'resources', and 'human health'. The weighing points associated with those substances and resources were depicted in Fig. 5. 

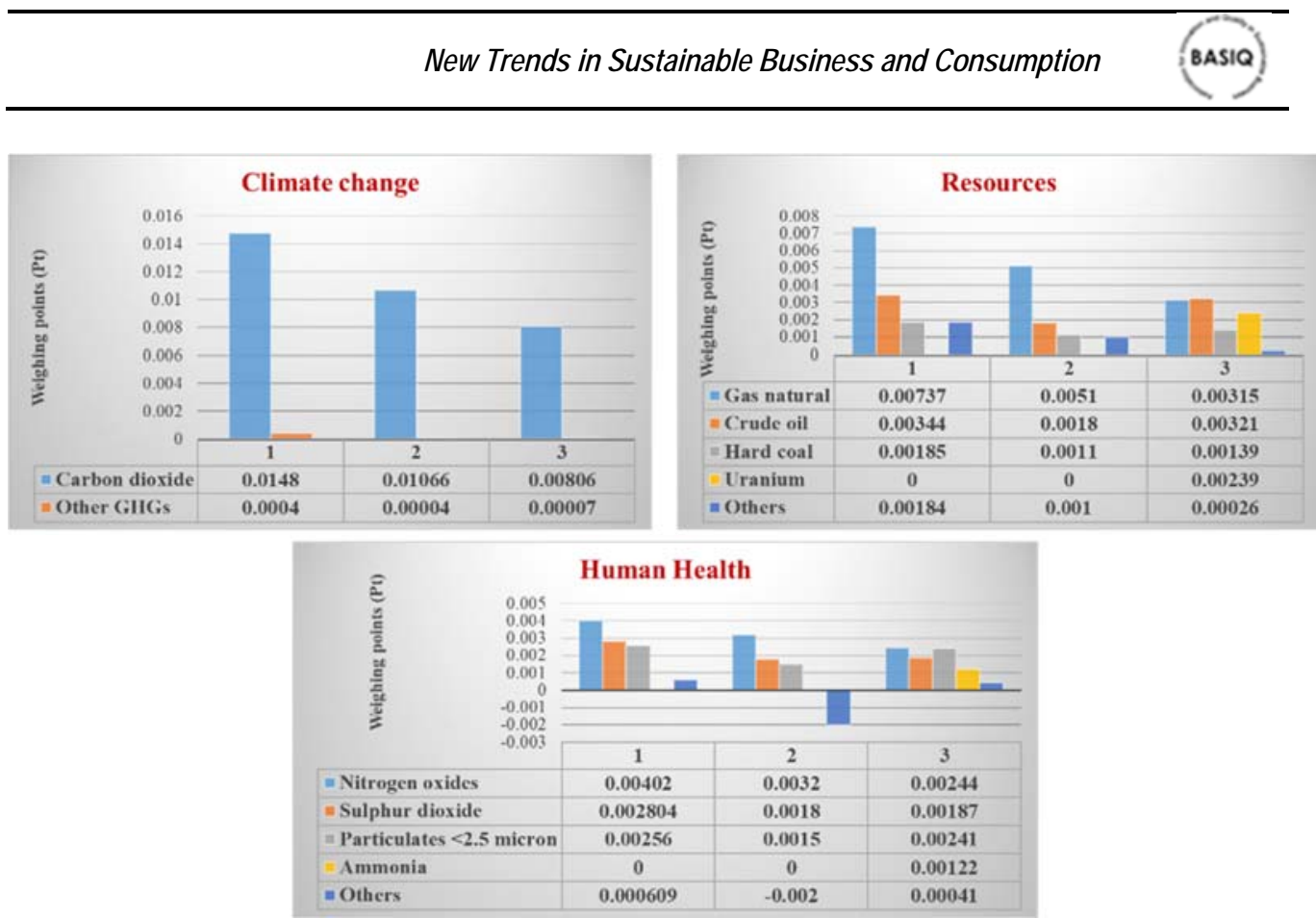

Figure no. 5. Most environmentally damaging substances emitted, and resources consumed for the three most affected damage categories within Impact 2002+.

\section{Conclusions}

The study attained the proposed goal of applying LCA to compare three external-wall solutions, constituted by different materials and put in place using different technologies, as the essential step to identify the best solution from both the energy and the environmental point of view.

Results show that, overall, walls 2 and 3 - and, especially, wall 3 - perform quite well in both energy and environmental terms, and can be considered as valid candidates for the design of environmentally sustainable and low-energy demanding buildings. The straw-based solution is the one that performs best from an energy and environmental perspective. Considering the both solutions present remarkable energy performances, the choice of one or the other is strictly depending upon the type of buildings that is designed, and the architectural and structural requirements it needs to fulfil.

Finally, thanks to this study the authors could observe that the usage of natural and recycled materials in easy-disassembly and recyclable compositions are clean construction solutions that can be considered as key design choices for environmental sustainable and low energy demanding buildings along their life cycles.

\section{References}

Chinnici, G., D’Amico, M., Rizzo, M., Pecorino, B., 2015. Analysis of biomass availability for energy use in Sicily. Renewable and Sustainable Energy Reviews, 52, pp.1025-1030.

Ciampi, M., Leccese, F., Tuoni, G., 2003. Ventilated façades energy performance in summer cooling of buildings. Solar Energy, 75, pp.491-502.

Compagno, L., Ingrao, C., Latora, A.G., Trapani, N., 2014. Life Cycle Assessment of CRT Lead Recovery Process. International Journal of Product Lifecycle Management, 7(2-3), pp.201-214.

Ingrao, C., Licciardello, F., Pecorino, B., Muratore, G., Zerbo, A., Messineo, A., 2018b. Energy and environmental assessment of a traditional durum-wheat bread. Journal of Cleaner Production, 171, pp.1494-1509. 
Ingrao, C., Lo Giudice, A., Tricase, C., Rana, R., Mbohwa, C., Siracusa, V., 2014. Recycled-PET fibre based panels for building thermal insulation: environmental impact and improvement potential assessment for a greener production. Science of the Total Environment 493, pp.914-929.

Ingrao, C., Messineo, A., Beltramo, R., Yigitcanlar, T, Ioppolo, G., 2018a. How can life cycle thinking support sustainability of buildings? Investigating life cycle assessment applications for energy efficiency and environmental performance. Journal of Cleaner Production, 201, pp.556-569.

Ingrao, C., Scrucca, F., Tricase, C., Asdrubali, F., 2016. A comparative Life Cycle Assessment of external wall-compositions for cleaner construction solutions in buildings. Journal of Cleaner Production, 124, pp.283-298.

International Organization for Standardization (ISO), 1994. Thermal insulation: Determination of Steady-state Thermal Transmission Properties: Calibrated and Guarded Hot Box. ISO 8990.

International Organization for Standardization (ISO), 2006a. Environmental Management - Life Cycle Assessment - Principles and Framework. ISO 14040.

International Organization for Standardization (ISO), 2006b. Environmental Management - Life Cycle Assessment - Requirements and Guidelines. ISO 14044.

International Organization for Standardization (ISO), 2007. Building Components and Building Elements: Thermal Resistance and Thermal Transmittance: Calculation Method. ISO 6946.

Jeswani, H.K., Azapagic, A., Schepelmann, P., Ritthoff, M., 2010. Options for broadening and deepening the LCA approaches. Journal of Cleaner Production, 12, pp.120-127.

Jolliet, O., Manuele, M., Raphael, C., Sebastian, H., Jérome, P., Gerald, R., Rosenbaum, R., 2003. IMPACT 2002+: a new life cycle impact assessment methodology. International Journal of Life Cycle Assessment, 8, pp.324-330.

La Rosa, A.D., Recca, A., Gagliano, A., Summerscales, J., Latteri, A., Cozzo, G., Cicala, G., 2014. Environmental impacts and thermal innovation performance of innovative composite solutions for building applications. Construction and Building Materials, 55, pp.406-414.

Malmqvist, T., Glaumann, M., Scarpellini, S., Zabalza, I., Aranda, A., Llera, E., Díaz, S., 2011. Life cycle assessment in buildings: the ENSLIC simplified method and guidelines. Energy, 36, pp. 1900-1907.

Pizzetti, C., 1986. Condizionamento dell'aria e refrigerazione. Teoria e calcolo degli impianti. Editore CEA.

Pulselli, R.M., Simoncini, E., Marchettini, N., 2009. Energy and energy based cost benefit evaluation of building envelopes relative to geographical location and climate. Building and Environment, 44, pp.920-928.

Rossi, B., Marique, A.F., Glaumann, M., Reiter, S., 2012. Life cycle assessment of residential buildings in three different European locations, basic tool. Building and Environment, 51, pp.4012-4407.

Stewart, J.P., 1948. Solar heat gain through walls and roofs for cooling load calculations. ASHVE Transactions, 54, pp.361-389. 